\title{
Training, assessment and accreditation in anaesthesiology and the implications for the European Union
}

Training, assessment and accreditation of anaesthesiologists within the European Union (EU) is generally well organized and of a high standard. However, variations occur, both within and between countries, for a number of reasons, almost all of which are related to issues outside the control of the medical profession. I believe that the quality aspirations of all those involved in anaesthesiology training in the EU would, given optimal circumstances, be the same. At present, each Member State organizes its own manpower planning, training schemes, assessment and accreditation processes, awarding national certificates of completion of anaesthesiology training, which in turn lead to inclusion on the country's 'Specialist Medical Register'. This degree of national independence is to be welcomed. Such training programmes vary in intensity, duration and assessment. Some include examinations, others include the testing of general and specific skills, and others still, have less clear end-points. The crucial factor is that, once a doctor is included on the Specialist Register, and provided these doctors obtained their primary medical qualification in an EU Member State, they are legally able to apply for inclusion on the Specialist Register of another EU Member State. Ironically, other anaesthesiologists, equally well qualified and on the Specialist Register of an EU Member State, but with their primary medical qualification in a non-EU country, cannot enjoy this freedom of exchange. To many of us, this is simply bureaucratic nonsense! So while centralized 'approval' of national training schemes would be welcome, the imposition of a single centralized and international training programme would be inappropriate.

As European anaesthesiologists, should we be concerned about this, and if so what should we be doing? Perhaps we should ask, what does the EU need and who should take the lead? Should it be the European

Correspondence to: Peter Simpson, Royal College of Anaesthetists, 48-49 Russell Square, London, UK, WC1B 4JY. E-mail: president@rcoa.ac.uk; Tel: +44 (0)20 7813 1900; Fax: +44(0)207813 1875

Accepted for publication July 2003 EJA 1610
Board of Anaesthesiology, under UEMS, or the proposed new confederation of ESA, European Academy of Anaesthesiology (EAA) and CENSA, or even a new body altogether? I believe that our objectives should be to raise the standards of anaesthesiology and its related disciplines, in Europe for the benefit of our patients, to improve training and assessment and to encourage scientific meetings and research. Greater uniformity of training, accreditation and assessment would facilitate additional opportunities for integration and harmonization, enhancement of professional standards, movement of professionals between countries and development of the speciality.

The current methods of assessment, training and accreditation in Europe vary between and even within countries. Individual Diplomas are awarded, different criteria for specialist recognition are used, different periods of training are required and there is variable recognition of other countries' qualifications and accreditation. In addition, Europe has some unique problems related to language, variable individual practice and resources and the supply and demand for doctors.

I believe that the European Academy should have a major role in the assessment of training and specialist recognition within Europe. There is great potential and opportunity for the expansion and use of the European Diploma, either as part of a national qualification process or as an internationally recognized qualification. It could be linked to hospital accreditation through the joint process, which already exists between the Academy and UEMS. The European Board, under UEMS, could and should establish criteria of Fellowship and even Membership, which would be open to all anaesthesiologists in Europe and would facilitate professional harmonization.

However, the European Diploma is only testing knowledge. If we accept that, in future, competence in a trainee should be assessed as the possession of the knowledge, skills and attitudes required to undertake safe clinical practice at a level commensurate with their stage of training, then the EDA would certainly fulfil the requirement for a test of knowledge, as part of competency-based training. Clinical skills would 
then be tested by work place assessment and attitudes and behaviour, the commonest single cause of failure to proceed, assessed against commonly agreed standards.

\section{So how could these suggestions be taken forward?}

There is no doubt that the time is ripe for the Specialist Anaesthetic Section of the UEMS, to formerly establish the title of Fellowship within the European Board of Anaesthesiology. The European Board of Anaesthesiology itself already exists as a Working Group of the UEMS Section of Anaesthesiology, Reanimation and Intensive Care as explained in Simon de Lange's Editorial in the European Journal of Anaesthesiology in 2001 [1]. Many UEMS Specialist Sections operate European Boards, from which European Board 'Fellowships' can be obtained (e.g. Certificate of Fellowship of the European Board of 'Speciality'). Although these 'Fellowships' have no legal standing and do not confer a right to practise in the EU, they are a mark of quality and excellence. However, in no way do they replace the national anaesthesiology qualifications of individual countries. Indeed, there is also no restriction based upon the nationality of the applicants. Essentially colleagues from any country in the world can be registered as 'Fellows' by the European Boards, just as in the case of the North American Boards [2].

It would seem therefore, that we, as anaesthesiologists within the Specialist Section of UEMS, have the opportunity to strengthen the existing European Board and to decide upon the qualifications for the award of Board Fellowship. We urgently need to move ahead on this issue, because much of the work done within our section at present is done in a vacuum, without the central focus of Board Fellowship. Guidelines for Continuing Education and Professional Development (CEPD), anaesthetic training, advice to the new accession countries of the EU about quality and structure of anaesthetic training programmes and even hospital visiting and accreditation would all be given so much more purpose if linked to a formal Board and to the attaining of a quality standard, by becoming Fellows. It is vital that the Specialist Anaesthetic Section of UEMS, through the Board, develops into a major influence in professional standards, training and accreditation.

\section{How could Board Fellowship be developed?}

Firstly, we must ask what are we trying to achieve? The Board is Europe-wide, not a national organization, so its Fellows should have an international perspective on issues and the Board will need to be able to take an equally international view. Secondly, we must decide whether we think the Board should be inclusive or exclusive? Do we want to include all those involved in specialist anaesthesiology practice in Europe? The answer here I feel, is that Board Fellowship is a title of distinction and a mark of quality and therefore any applicant who fills the admission requirements should be able to become a Fellow. That said, and in the interests of inclusivity, I believe that there should be a second category of membership, open to all and from which suitable candidates could aspire to Fellowship.

If this is to be achieved, several important points need to be clarified:

1. The work and structure of the Board must be seen to be relevant to EU anaesthesiology.

2. The title of Fellow must be a title of distinction and a mark of individual excellence.

3. The title of Fellow must not be devalued by awarding it to everyone; particularly those who only intend to work in Europe for a short time.

4. Board Fellowship must also be achievable and attainable by a significant number of suitably qualified anaesthesiologists. It must not be perceived as elitist and only ever available to a few anaesthesiologists who, somehow, 'have the right connections'.

Various routes of admission to Fellowship of the European Board of Anaesthesiology (FEBA) might be considered, given that it should be considered as a mark of excellence, coming on top of the national qualification as a medical specialist. If applications were organized by a Nominations Committee of the Board, I firmly believe that excellence could be maintained through the following routes of admission to Fellowship, if the criteria set down were suitably robust.

\section{Possible routes of admission to Board Fellowship}

\section{Examination}

Holders of international European qualifications in anaesthesiology, for example the European Diploma of Anaesthesiology and Intensive Care, who are, by definition, on the Specialist Register of a European country. This means that although the examination only tests knowledge, candidates will already have had their skills and attitudes assessed and accredited as part of their national qualification process.

\section{Academic}

1. Senior academics in anaesthesiology departments in a European Member State, for example Professors, Readers, Senior Lecturers. 
2. Academicians of the EAA.

3. Individual academic nominations to the Nominations Committee.

\section{Training and accreditation}

Permanent specialist members of anaesthesiology departments visited and accredited under the UEMS/ EAA hospital visiting programme. Clear rules about anaesthesiologists who work for a time in an accredited hospital and then go elsewhere in the world would have to be established, and whether and for how long such people can use the title of FEBA.

\section{National nomination}

National specialist societies could have the opportunity to nominate individual anaesthesiologists of distinction to the Nominations Committee of the Board, for approval and award of the title. Limits could be set for individual countries based on criteria, such as total patient population, number of anaesthesiologists or a maximum number of nominations per year.

\section{How could the Board be further developed?}

In the interests of inclusiveness and unity of our Speciality, I believe that, if we are considering the proposals above, we should also introduce a category of Membership of the European Board (MEBA). This could be by application and open to all those on the Specialist Anaesthesiology Register of a European Member State. Members of the Board, of say 10 years of specialist anaesthesiology practice, would then be able to apply and be considered for Fellowship status, with the support of their National Anaesthesiology
Society. Although, to my knowledge, this has not been considered before, I do not see that it would contravene the terms under which a UEMS Specialist Section Board operates. Furthermore, I believe it has three major advantages:

1. That all individuals involved in European anaesthesiology will feel part of a single Professional Specialist organization.

2. Board Membership and Fellowship will be seen to be attainable by everyone.

3. The distinct title of Fellow, denoting excellence will be enhanced.

As often happens, our speciality has the opportunity to take a lead in what I believe is an exciting and unifying venture for anaesthesiology in a new and expanding Europe. The attainment and recognition of excellence is what we would want for our patients and here is a golden opportunity to achieve it.

$$
\begin{array}{r}
\text { Peter Simpson } \\
\text { Chairman of Examinations } \\
\text { European Academy of Anaesthesiology } \\
\text { Richmond, UK } \\
\text { President } \\
\text { Royal College of Anaesthetists } \\
\text { London, UK }
\end{array}
$$

\section{References}

1. de Lange S. The European Union of Medical Specialists and speciality training. Eur J Anaesthesiol 2001; 18: 561-562.

2. UEMS Specialist Sections and European Boards Meeting with the UEMS Executive Committee, 11th May 2002, Item 4 'Status European Board Qualifications (D0048)'. 